\title{
AVALIÇÃO DO CONTEÚdO DE PROTEÍNAS E GRUPOS SULFATOS PRESENTES EM DIFERENTES FRAÇÕES DA MACROALGA KAPPAPHYCUS ALVAREZII
}

\author{
A. T. MITSUHARA, L. V. S. SACRAMENTO, R. MONTI e F. MASARIN
}

Faculdade de Ciências Farmacêuticas - FCF - UNESP - Campus Araraquara, a.mitsuhara@gmail.com, Processo FAPESP nº. 2014/12519-3.

\begin{abstract}
RESUMO - A macroalga Kappaphycus alvarezii possui grandes quantidades de carboidratos e outros compostos em menores quantidades (cinzas, grupos sulfatos e proteínas). A avaliação das quantidades de proteínas e grupos sulfatos por um método confiante e de baixo custo é fundamental para estudos de fracionamento da biomassa de $K$. alvarezii visando a produção de biocombustíveis e/ou bioprodutos de interesse comercial. $\mathrm{O}$ presente trabalho avaliou diferentes métodos para medir os conteúdos de proteínas totais e grupos sulfato em diferentes frações da biomassa da cepa marrom de $K$. alvarezii. Foram utilizados três métodos para determinação de proteínas (Lowry, Kieldahl e Análise elementar) e dois métodos para determinação de grupos sulfato (Espectrofotométrico e Análise elementar). Os teores de grupos sulfato foram similares entre os dois métodos avaliados. A amostra não tratada, tratada com $\mathrm{KOH}$, resíduo e carragena semi-refinada mostraram valores médios de grupos sulfato (considerando os dois métodos avaliados) de 9.8\%, 10,0\%, 7,0\% e 14,8\%, respectivamente. Houve variação nos valores de proteínas nas amostras em estudo entre os três métodos avaliados. O teor proteínas utilizando-se a metodologia de Lorwy foi considerada mais exata e mostrou valores médios de proteínas de $4.7 \%$, $1.4 \%, 1.2 \%$ e $1.6 \%$ na amostra não tratada, tratada com $\mathrm{KOH}$, resíduo e carragena semi-refinada, respectivamente.
\end{abstract}

\section{INTRODUÇÃOO}

Os biocombustíveis representam um tema de grande repercussão internacional devido à dependência de derivados do petróleo para a produção de energia e sua consequência nas mudanças climáticas do planeta. Nesse cenário, o Brasil tem uma excelente oportunidade para atuar em novas matrizes energéticas associadas à produção de combustíveis e produtos químicos através de fontes renováveis. Atualmente, grandes quantidades de etanol são produzidas a partir da sacarose de cana de açúcar. O uso de materiais lignocelulósicos para a produção de biocombustíveis e produtos químicos têm muitas vantagens em termos de disponibilidade de recursos, considerando a grande quantidade de materiais lignocelulósicos produzidos por atividades florestais e de agricultura. Entretanto, os materiais lignocelulósicos são muito recalcitrantes frente à hidrólise enzimática de polissacarídeos, sendo necessário primeiro um pré-tratamento químico do material e posteriormente a hidrólise enzimática para conversões acima de 30\% (Mendes et al., 2011). Outra fonte renovável que poder ser utilizada para a produção de biocombustíveis são as algas, que também podem ser cultivadas 
em grandes quantidades no Brasil. As algas são plantas terrestres e aquáticas e muitas espécies contem altos teores de carboidratos e baixo conteúdo de lignina e no futuro próximo essa fonte se tornará essencial para o uso em processos biotecnológicos de fermentação (Wi et al., 2009; Martone et al., 2009; Ge et al., 2011; Jon et al,. 2011; Wei et al., 2012). Além disso, alguma espécie de algas também contém lipídeos que podem ser pré-extraídos e utilizados para a produção de biodiesel (Ahmad et al., 2011).

Devido ao baixo conteúdo de lignina em algas os polissacarídeos são mais acessíveis a tratamentos químicos e enzimáticos o que torna as algas menos recalcitrantes do que as plantas terrestres (Wi et al., 2009; Jon et al., 2011; Harum et al., 2011; Masarin et al., 2011). As algas também produzem mais oxigênio do que utilizam na respiração ao contrário das plantas terrestres. Desta forma, as algas têm um ganho ambiental que pode ser convertido em um ganho econômico com a comercialização de créditos de carbono. Além disso, em média as algas têm uma produtividade de $22 \mathrm{~kg} . \mathrm{m}^{-2} /$ ano (dados em base seca) superiores as plantas terrestres que tem uma produtividade média de 0.5-4.4 kg.m $\mathrm{m}^{-2} /$ ano (dados em base seca) (Brinkhuis et al., 1987; Lewandowski et al., 2003; Wi et al., 2009). Nesse contexto, o presente trabalho propôs avaliar diferentes métodos para a determinação dos conteúdos de proteínas e grupos sulfatos na biomassa não tratada e frações oriundas do processamento de carragena semi-refinada da cepa marrom da macroalga $K$. alvarezii.

\section{MATERIAIS E MÉTODOS}

A Figura 1 mostra um fluxograma geral que representa como foram obtidas as amostras avaliadas no presente estudo.

Figura 1 - Fluxograma geral de obtenção das frações estudadas.

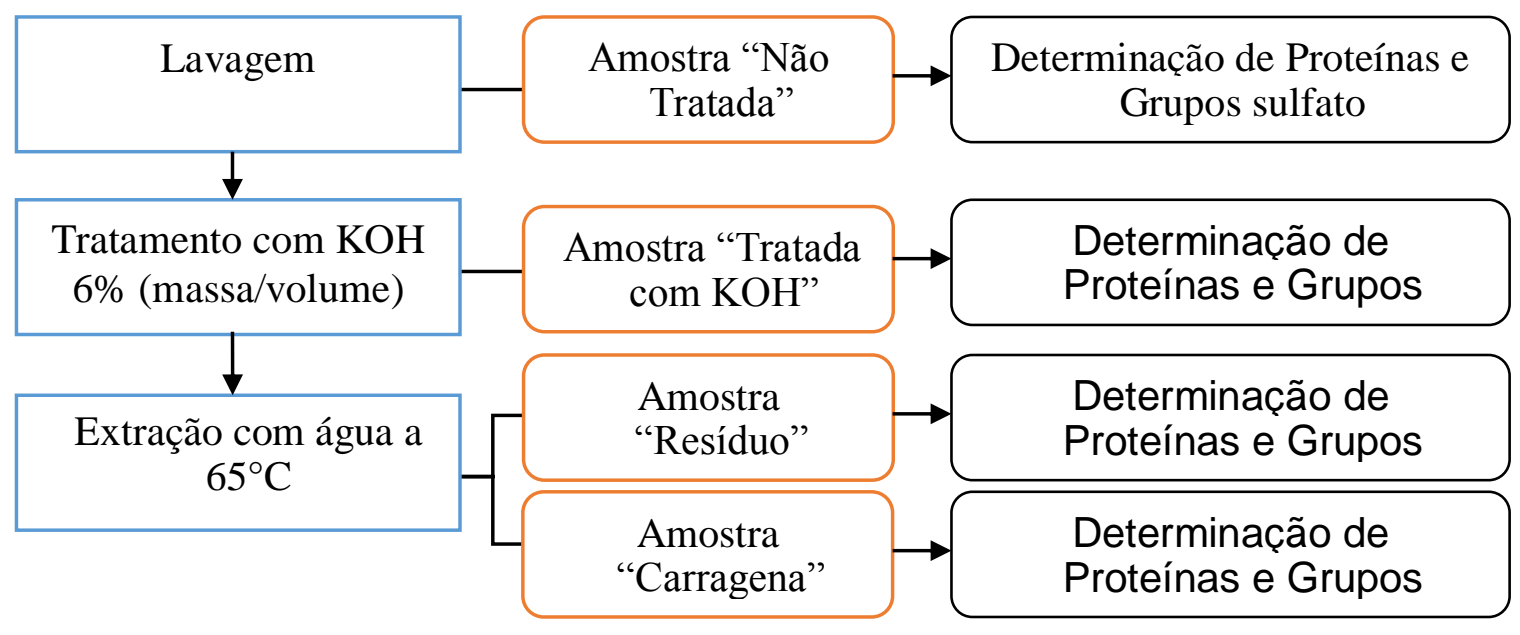

A biomassa da cepa marrom de $K$. alvarezii foi processada e foram obtidas as seguintes frações: amostra não tratada, trada com $\mathrm{KOH}$, resíduo e carragena semi-refinada (Figura 1). Os rendimentos obtidos em cada uma dessas etapas foram reportados na literatura recente (Masarin et al., 2016). Para a determinação dos conteúdos de proteínas pelos métodos de Lowry, Kieldahl e Análise elementar as amostras foram previamente moídas em moinho de 
facas para homogeneização $(0.84 \mathrm{~mm})$. Para o método de Kieldahl as amostras foram digeridas com ácidos para a determinação de nitrogênio total (Masarin et al. 2016), porém foi utilizado um fator de 4.92 para a determinação dos teores de proteínas (Lourenço et al. 2002). Para o método de Lorwy, $200 \mathrm{mg}$ das amostras foram pesadas em tubos de ensaios e tratadas com $\mathrm{NaOH} 1 \mathrm{M}$ a $70^{\circ} \mathrm{C}$ por $4 \mathrm{~h}$ para dissolver as proteínas (Hartree,1972). Para a o método de Análise elementar foi pesado aproximadamente $1 \mathrm{mg}$ de amostra em balança analítica com 5 casas decimais e analisado no equipamento EA 1108 Fisons CHNS microanálises, para o cálculo de proteínas totais foram utilizados os valores de nitrogênio total de cada amostra em estudo e o fator de 4.92 (Lourenço et al. 2002). Para a determinação de grupos sulfatos foram utilizados dois métodos (Espectrofotométrico e Análise Elementar). O método espectrofotométrico foi realizado segundo reportado na literatura recente (Masarin et al., 2016). O método de Análise elementar para determinação do conteúdo de grupos sulfato utilizou a mesma técnica de determinação de proteínas, porém foi determinado o valor total de átomos de enxofre, que foi utilizado para o cálculo de grupos sulfatos (Masarin et al., 2016).

\section{RESULTADOS E DISCUSSÃO}

A Tabela 1 apresenta os teores de proteínas e grupos sulfato nas diferentes frações estudadas: não tratada, tratada com $\mathrm{KOH}$, resíduo e carragena semi-refinada. O método de Análise elementar apresentou um teor relativamente superior de proteínas em todas as frações em estudo quando comparado ao método de Lorwy e Kjeldahl (Tabela 1). Os menores conteúdos de proteínas encontrados pelo método de Lorwy podem ser atribuídos à presença de compostos inorgânicos (contendo o nitrogênio em sua estrutura) presentes nas amostras em estudo, pois essa técnica não detecta nitrogênio em compostos inorgânicos. Outra hipótese poderia ser atribuída ao fato de que o método de Lorwy pode ter sido afetado por interferentes na solução após a extração das proteínas, como por exemplo, compostos fenólicos e açúcares, que poderia causar um resultado falso positivo quando comparado ao método de Kjeldahl (Zaia et al., 1998). Entretanto, o menor conteúdo obtido pelo método de Kjeldahl pode ser atribuído a uma possível ineficiência de extração da fase orgânica, pois as proteínas de macroalgas são associadas a membranas celulares de difícil extração (Lourenço et al. 2002). Os teores de grupos sulfato foram similares entre os dois métodos testados nas frações em estudo (Tabela 1).

Tabela 1 - Teores de proteína e grupos sulfato nas diferentes frações de $K$. alvarezii. Dados apresentados em porcentagem (gramas/100 gramas de material, dados em base seca).

\begin{tabular}{|c|c|c|c|c|c|}
\hline \multirow[b]{2}{*}{ Amostras } & \multicolumn{2}{|c|}{ Proteínas } & \multicolumn{3}{|c|}{ Grupos sulfato } \\
\hline & Lowry (\%) & Kjeldahl (\%) & $\begin{array}{c}\text { Anál. Elem. } \\
(\%)\end{array}$ & $\begin{array}{c}\text { Espectro. } \\
(\%)\end{array}$ & $\begin{array}{c}\text { Anál. Elem. } \\
(\%)\end{array}$ \\
\hline Não tratada & $4.7 \pm 0.1$ & $3.0 \pm 0.3$ & $8.9 \pm 0.7$ & $9.4 \pm 0.4$ & $10.3 \pm 0.7$ \\
\hline Tratada $\mathrm{KOH}$ & $1.4 \pm 0.1$ & $0.4 \pm 0.1$ & 3.0 & $10.8 \pm 0.3$ & 9.3 \\
\hline Resíduo & $1.2 \pm 0.1$ & $0.4 \pm 0.1$ & 3.2 & $8.1 \pm 0.2$ & 5.9 \\
\hline $\begin{array}{c}\text { Carragena } \\
\text { semi-refinda }\end{array}$ & $1.6 \pm 0.1$ & $0.2 \pm 0.1$ & 2.7 & $13.8 \pm 0.2$ & 15.9 \\
\hline
\end{tabular}




\section{CONCLUSÃO}

Em resumo, os conteúdos de proteínas nas frações de $K$. alvarezii podem variar dependendo do método utilizado. O método de Lorwy pode ser admitido como mais exato, pois não há indicativos de interferentes na biomassa de $K$. alvarezii. Além disso, esse método não detecta a presença de inorgânicos contendo nitrogênio, como pode ocorrer nos métodos de Análise elementar e Kjeldahl. Em relação aos dois métodos avaliados para detectar os conteúdos de grupos sulfato podemos admitir que ambos são eficientes.

Desta forma, o método de Lorwy e o método espectrofotométrico podem ser utilizados para medir os conteúdos de proteínas e grupos sulfatos em biomassa de $K$. alvarezii, respectivamente. Ambos os métodos são considerados espectrofotométricos e de baixo custo, pois utilizam padrões autênticos e um espectrofotômetro simples que são encontrados na maioria dos laboratórios de pesquisa.

\section{REFERÊNCIAS}

AHMAD, A. L; YASIN, N. H. M; DEREK, C. J. C; LIM, J. K. Microalgae as a sustainable energy source for biodiesel production: A review. Renew sust. energ. rev., v. 15, p. 584$593,2011$.

BRINKHUIS, B. H.; LEVINE, H. G.; SCHLENK, G. G.; TOBIN, S. Laminaria cultivation in the far east and north America. In: Bird, K.T; Benson, P. H. (Eds.), Seaweed Cultivation for Renewable Resources, Amsterdam, p. 107-146, 1987.

GE, L.; WANG, P.; MOU, H. Study on saccharification techniques of seawwed wastes for the transformation of ethanol. Renew. Energ., v. 36, p. 84-89, 2011.

HARTREE, E. F. Determination of protein: a modification of the Lowry method that gives a linear photometric response. Anal Biochem., v. 48, p. 422-427, 1972

HARUN, R.; DANQUAH, M. K. Influence of acid pre-treatment on microalgal biomass for bioethanol production. Process Biochem, v. 46, p. 304-309, 2011.

JOHN, R. P.; ANISHA, G. S.; NAMPOOTHIRI, K. M.; PANDEY, A. Micro and macroalgal biomass: A renewable source for bioethanol. Bioresour Technol, v. 102, p. 186-193, 2011.

LEWANDOWSKI, L.; SCURLOCK, J. M. O.; LINDVALLC, E.; CHRISTOUD, M. The development and corrent statusof perennial rhizomatous grasses as energy crops in the US na Europe. Biomass Bioenerg., v. 25, p. 335-361, 2003.

LOURENÇO, S. O., BARBARINO, E., DE-PAULA, J. C., PEREIRA, L. O. S., MAEQUEZ, U. M. L. Amino acid composition, protein content and calculation of nitrogen-to-protein conversion factors for 19 tropical seaweeds. Phycol. Res. v.50, p. 233-241, 2002. 
MARTONE, P.T.; ESTEVES, J.M; LU, F; RUEL, K; DENNY, M.W; SOMERVILLE, C; RALPH, J. Discovery of lignin in seawwed reveals convergent evolution of cell-wall architecture. Curr. Biol., v. 19, p. 169-175, 2009.

MASARIN, F., CEDENO, F. R. P., CHAVEZ, E. G. S., DE OLIVEIRA, L. E., GELLI, V. C., MONTI, R., Chemical analysis and biorefinery of red algae Kappaphycus alvarezii for efficient production of glucose from residue of carrageenan extraction process. Biotechnol Biofuels. v. 9 (122), p.1-12, 2016.

MASARIN, F; GURPILHARES D.B; BAFFA, D.C.F; BARBOSA, M.H.P; CARVALHO, W; FERRAZ, A; MILAGRES, A. M. F. Chemical composition and enzymatic digestibility of sugarcane clones selected for varied lignin content. Biotechnol. Biofuels, v.4, p. 55, 2011.

MENDES, M.F; SIQUEIRA, G; CARVALHO, W; FERRAZ, A; MILAGRES, M.F.A. Enzymatic Hydrolysis of Chemithermomechanically Pretreated Sugarcane Bagasse and Samples with Reduced Initial Lignin Content. Biotechnol. Progr., v. 27, p. 395-401, 2011.

WEI, N; QUARTERMAN, J; JIN, Y.S. Marine macroalgae: na untapped resource for producing fuels and chemicals. Cell Press, v. 31, p. 70-77, 2012.

WI, S. G.; KIM, H. J.; MAHADEVAN, S. A.; YANG, D. J; BAE, H. J. The potential value of the seaweed Ceylon moss (Gelidium amansii) as an alternative bioenergy resource. Bioresour. Technol., v. 100, p. 6658-6660, 2009.

ZAIA D. A. M., ZAIA, C. T. B. V., LICHTIG J. Determination of total protein by spectrophotometry: advantages and disadvantages of proposed. Quím. Nova. v. 21(6), p.787-793, 1998. 